$\underline{\xi}=-m$

\title{
Teratogenic effects of imidacloprid in rats: mechanistic role of oxidative stress
}

\author{
Nermeen Borai El-Borai ${ }^{1}$ *, Seham Said Hadad ${ }^{2}$, Hanem Kamal Khalifa ${ }^{3}$ \\ ${ }^{1}$ Department of Forensic Medicine and Toxicology, Faculty of Veterinary Medicine, University of Sadat City, Sadat City, 32897, Egypt \\ ${ }^{2}$ Department of Anatomy \& Embryology, Faculty of Veterinary Medicine, University of Sadat City, Sadat City, 32897, Egypt \\ ${ }^{3}$ Department of Biochemistry and Chemistry of Nutrition, Faculty of Veterinary medicine, University of Sadat City, 32897, Egypt \\ *Corresponding author E-mail: nermeenborai@yahoo.com
}

\begin{abstract}
Extensive use of imidacloprid (IMI) insecticide in the agro-vet practices leads to continuous animal and human exposure. Exposure of pregnant dams to such insecticides results in fetal malformations. In the light of this, the present study was designed to investigate the teratogenic effects of two different doses of IMI and the possible mechanistic role of oxidative stress. Fifteen pregnant females were randomly divided into three equal groups and orally treated daily during organogenesis period (6-15th GD), control (distilled water), LDIMI $(45 \mathrm{mg} / \mathrm{kg})$ and HD-IMI $(90 \mathrm{mg} / \mathrm{kg})$. All pregnant dams were exposed to caesarean section on GD 20. Exposure to IMI induced significant increase in the percentage of resorptions at high-dose with significant reduction of fetal and placental weights in a dosedependent manner. External fetal morphological abnormalities were recorded only at high-dose while several visceral abnormalities were observed in fetuses at low- and high-doses. Significant increases in the percentages of fetal skeletal malformations were recorded only in the high-dose group. Significant changes in MDA, GSH levels and CAT activity with insignificant change in the level of $\mathrm{H}_{2} \mathrm{O}_{2}$ were recorded only in placentae of LD-IMI group. However, all these parameters recorded significant changes in serum of dams, placentae and liver of fetuses at high-dose. In conclusion, exposure of pregnant rats to IMI, particularly at higher-dose, during the period of organogenesis induced fetal teratogenic effects that may be related to its maternal and fetal oxidative damaging impacts.
\end{abstract}

Keywords: Imidacloprid; Malformations; Oxidative Stress; Placenta; Teratogenicity.

\section{Introduction}

Insecticides, the most widespread category of pesticides, are agents used globally in various industrial, agriculture, household, and veterinary practices (Hamid et al., 2012). Insecticides are potent and toxic environmental pollutants that exert public health problems through crop, soil, and water contamination (Adjrah et al., 2013).

Neonicotinoids are a commercially recent class of insecticides that are extensively used instead of organophosphates, organochlorines, and carbamates insecticides, which are more harmful for mammals (Simon-Delso et al., 2015). Imidacloprid (IMI), the best known synthetic neonicotinoids targeting nicotinic acetylcholine receptors (nAChRs), is characterized by its high intrinsic insecticidal potency, its selective toxicity for insects and its low toxicity for mammals, so it is ranked as one of the highest production and the top selling insecticides (Tomizawa and Casida, 2005; Hussein et al., 2014).

Animals and human are possibly exposed to neonicotinoids including IMI due to their extensive use in agriculture and veterinary fields (Jeschke et al., 2011; Goulson, 2013; Otranto et al., 2016) resulting in their persistence in soil, ground water and wide range of fruits and vegetables (Bonmatin et al., 2015).

Although IMI has low mammalian toxicity (Anatra-Cordone and Durkin, 2005), many studies have plainly proved its hepatotoxic, nephrotoxic, neurotoxic, immunetoxic and genotoxic effects (Mohany et al., 2011; Lonare et al., 2014; Arfat et al., 2014; Bagri et al., 2016). Imidacloprid exerts its toxic effects mainly through the oxidative metabolites and/or free radicals that produced during its metabolism leading to lipid peroxidation and depletion of antioxidant enzymes, and consequently, oxidative tissue damages (Kapoor et al., 2010).

Repeated exposure to IMI increases the risks of male and female reproductive toxic effects (Bal et al., 2012; Vohra and Khera, 2015), also causes neurobehavioral deficits and malformations in rats' offsprings following in utero exposure (Abou-Donia et al., 2008; Gawade et al., 2013).

Despite that both animals and humans are intensely exposed to neonicotinoids insecticides, there are little data available on their teratogenic effects. Therefore, this study aimed to elucidate the teratogenic effects (i.e. morphological, visceral, and skeletal abnormalities) of two different doses of IMI and the possible mechanistic role of oxidative stress. 


\section{Materials and methods}

\subsection{Chemicals}

Commercial grade Imidacloprid (Imidamex 70\% wg), MAC-GmbH Company, Germany. Diagnostic kits for biocemical analysis were purchased from Biodiagnostic Company, Dokki, Giza, Egypt. All other chemicals were purchased from Sigma-Aldrich Chemical Company (Saint Louis, Missouri, USA).

\subsection{Animals}

A healthy adult mature males and females Wistar albino rats (180-200 g) were obtained from Al-Zyade Experimental Animals Production Center (Giza, Egypt). All animals were allocated into plastic cages on wood-chip bedding at well ventilated laboratory animal room $\left(22 \pm 3^{\circ} \mathrm{C}, 45-60 \%\right.$ relative humidity, natural daily dark/light cycle) with ad libitum access to food and water and kept for acclimatization 2 weeks before the experiment. The experimental protocol was ethically approved by the International Animal Care and Use Committee, Faculty of Veterinary Medicine, University of Sadat City.

\subsection{Mating}

Female rats were kept overnight with males at the ratio of $2: 1$. In the early morning, vaginal smears from female rats were inspected immediately under microscope. Existence of sperm in the vaginal smear of the mated females indicated successful mating and these females were considered to be in gestational day zero (GD 0) (Paumgartten et al., 1998).

\subsection{Experimental design}

Fifteen pregnant females were randomly divided into three equal groups, weighed and treated orally once daily on GD 6 through GD 15 (i.e, organogenesis period). Control group, rats were administrated distilled water, LD-IMI and HD-IMI groups, rats were administrated IMI at a dose of 45 and $90 \mathrm{mg} / \mathrm{kg}$, respectively. The doses of IMI were equivalent to $1 / 10$ and $1 / 5$ of the oral LD 50 of IMI (450 mg/kg) in rat (Singh et al., 2013).

\subsection{Sampling}

On GD 20, the dams were anesthetized, sacrificed for blood samples collection and serum isolation, and then submitted to laparotomy process. The uterine horns were exposed and the numbers of uterine implants (resorption sites and number of live/ dead fetuses) were counted for each dam. The uterus of each dam was excised, opened using a scissor and then the fetuses and placentae were separated and weighed. One fetus and one placenta from each dam were stored at $-20^{\circ} \mathrm{C}$ for further biochemical investigations, while the other fetuses were used for morphological, visceral, and skeletal fetal examinations.

\subsection{Fetal examination}

After weighing the fetuses of pregnant dams, all fetuses examined for morphological abnormalities. One third of the obtained fetuses were kept in Bouin's solution for at least one week, after which, fetuses were sectioned using free-hand razor blade sectioning technique for internal visceral malformations examination. The other two thirds were kept in $95 \%$ ethanol, eviscerated, cleared in $1 \% \mathrm{KOH}$ and finally stained using Alizarin red S stain for subsequent preparation of skeletal examination (Manson and Kang, 1994).

\subsection{Biochemical analysis}

Malondialdehyde (MDA) (Ohkawa et al., 1979), reduced glutathione (GSH) (Beutler et al., 1963), hydrogen peroxide $\left(\mathrm{H}_{2} \mathrm{O}_{2}\right)$ and catalase (CAT) (Aebi, 1984) contents were spectrophotometrically assayed in serum of dams, and tissue homogenates of placenta and liver of fetuses using commercial kits and following the manufacturer's instructions.

\subsection{Statistical analysis}

All statistical analyses were performed using SPSS Version 16 released on 2007. Uterine findings, fetal and placental weights as well as biochemical analysis were analyzed by one way ANOVA and followed by Duncan's Multiple Range test for post hoc analysis. Morphological, visceral and skeletal malformations were analyzed by Chi square. Data were expressed as percentages and mean \pm standard error (SE), Differences were considered statistically significant at $\mathrm{P}<0.05$.

\section{Results}

\subsection{Effects on general health of pregnant dams}

Dams orally administrated low- (45 mg/kg b.w, $1 / 10$ LD 50$)$ and high- (90 mg/kg b.w, 1/5 LD50) doses of IMI during the period of organogenesis $\left(6^{\text {th }}-15^{\text {th }}\right.$ day of gestation period) did not show any mortalities or apparent signs of toxicity except, rough body coat and depression, that were notable in high-dose group.

\subsection{Effects on maternal and fetal indices}

The uterus of pregnant dams in control and LD-IMI groups did not show any resorption sites, while significant increase $(\mathrm{P}<0.05)$ in the percentage of resorption sites (Fig. 1) was recorded in HD-IMI group, being $13.04 \%$, compared to that of the control and low-dose groups. However, exposure of dams to low- or high-doses of IMI had no effect on the number of live fetuses (Table 1). 
In control group, the mean values of fetal and placental weights were $4.00 \pm 0.06$ and $0.45 \pm 0.01$, respectively. These values were significantly reduced $(\mathrm{P}<0.05)$ in a dose-dependent manner, being $2.88 \pm 0.09$ and $0.35 \pm 0.02$ in the low-dose and $2.17 \pm 0.17$ and $0.31 \pm 0.01$ in the high-dose groups, respectively. Also, there was significant change in these values between low- and high-dose groups (Table 1).

Table 1: Maternal and Fetal Indices of Control and Treated Dams

\begin{tabular}{|c|c|c|c|c|c|c|c|c|}
\hline \multirow{2}{*}{ Group } & \multirow{2}{*}{$\begin{array}{c}\text { No. of } \\
\text { pregnant dams }\end{array}$} & \multirow{2}{*}{$\begin{array}{l}\text { No. of uterine } \\
\text { implants }\end{array}$} & \multicolumn{2}{|c|}{ Resorption sites } & \multicolumn{2}{|c|}{ Live fetuses } & \multirow{2}{*}{$\begin{array}{l}\text { Mean fetal } \\
\text { weights } \\
\text { (g) }\end{array}$} & \multirow{2}{*}{$\begin{array}{l}\text { Mean placental } \\
\text { weights } \\
\text { (g) }\end{array}$} \\
\hline & & & No & $\%$ & No & $\%$ & & \\
\hline Control & 5 & 49 & 0 & 0 & 49 & 100 & $4.00 \pm 0.06$ & $0.45 \pm 0.01$ \\
\hline LD-IMI & 5 & 46 & 0 & 0 & 46 & 100 & $2.88 \pm 0.09^{\mathrm{a}}$ & $0.35 \pm 0.02^{\mathrm{a}}$ \\
\hline HD-IMI & 5 & 46 & 6 & $13.04^{\mathrm{a}, \mathrm{b}}$ & 40 & 100 & $2.17 \pm 0.17^{\mathrm{a}, \mathrm{b}}$ & $0.31 \pm 0.01^{\mathrm{a}, \mathrm{b}}$ \\
\hline
\end{tabular}

Data are presented as Mean \pm SE Unless Otherwise Stated a: Significant difference between control and LD-IMI or HD-IMI groups, and b: Significant difference between LD-IMI and HD-IMI groups at $\mathrm{P}<0.05$. LD-IMI: low dose-imidacloprid; HD-IMI: high dose- imidacloprid.

\subsection{Teratogenic effects}

\subsubsection{Fetal morphological malformations}

No external morphological malformations were recorded in fetuses from dams of control or LD-IMI groups. Nevertheless, various external fetal morphological malformations, including dwarfed fetuses (Fig. 2A), s/c hemorrhage (Fig. 2B) and s/c edema (Fig. 2C) were recorded in HD-IMI group. The significant increases $(\mathrm{P}<0.05)$ were only recorded in the percentages of dwarfed fetuses and s/c edema, being $27.5 \%$ and $10 \%$, respectively, compared to those of control and LD-IMI groups (Table 2).

Table 2: Fetal Morphological Malformations of Control and Treated Dams

\begin{tabular}{|c|c|c|c|c|c|c|c|}
\hline \multirow[b]{3}{*}{ Group } & \multirow{3}{*}{$\begin{array}{c}\text { No. of } \\
\text { examined } \\
\text { live fetuses }\end{array}$} & \multicolumn{6}{|c|}{ External morphological malformations } \\
\hline & & \multicolumn{2}{|c|}{ Dwarfism } & \multicolumn{2}{|c|}{ s/c Hemorrhage } & \multicolumn{2}{|c|}{ s/c Edema } \\
\hline & & No & $\%$ & No & $\%$ & No & $\%$ \\
\hline Control & 49 & 0 & 0 & 0 & 0 & 0 & 0 \\
\hline LD-IMI & 46 & 0 & 0 & 0 & 0 & 0 & 0 \\
\hline HD-IMI & 40 & 11 & $27.51^{\mathrm{a}, \mathrm{b}}$ & 3 & 7.5 & 4 & $10^{\mathrm{a}, \mathrm{b}}$ \\
\hline
\end{tabular}

Data are presented as percentages of morphologically deformed fetuses in relation to the total number of the examined live fetuses a: Significant difference between control and LD-IMI or HD-IMI groups and b: Significant difference between LD-IMI and HD-IMI groups at $\mathrm{P}<0$.05. LD-IMI: low dose-imidacloprid; HD-IMI: high dose- imidacloprid.

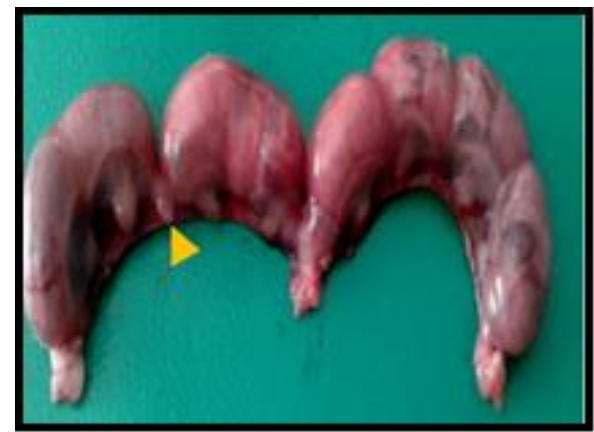

Fig. 1: Uterus of a Pregnant Rat Treated Orally with a High Dose of IMI $\left(90 \mathrm{mg} / \mathrm{kg}, 1 / 5 \mathrm{LD}_{50}\right)$ on Days 6-15th of Gestation Showing Resorption Site on The Left Horn (arrow).

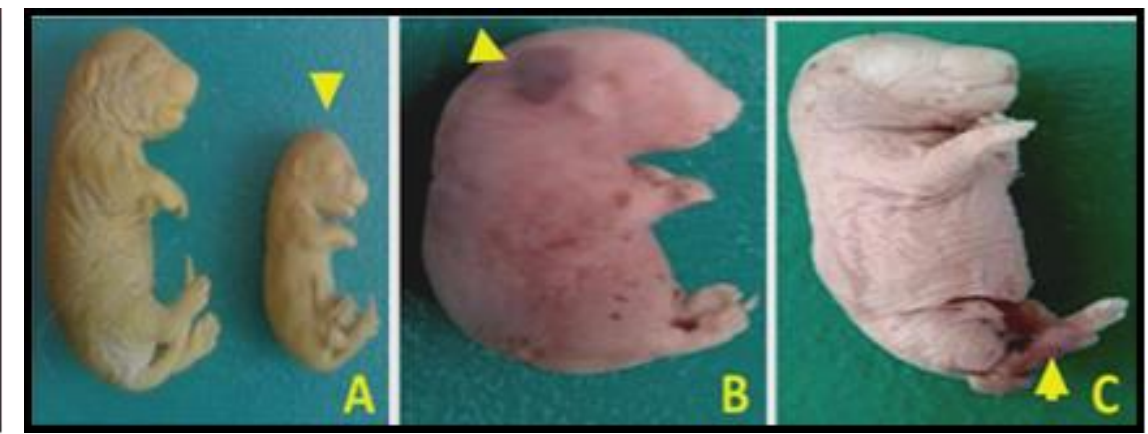

Fig. 2: Rat Fetuses (Right) Obtained from Dams Treated Orally with High Dose of IMI (90 $\mathrm{mg} / \mathrm{kg}, 1 / 5 \mathrm{LD}_{50}$ ) on Days 6-15th of Gestation Showing: A: Dwarfism, B: s/c Hemorrhages, C: s/c Edema.

\subsubsection{Fetal visceral malformations}

No visceral malformations were recorded in fetuses of control group except only one fetus exhibited dilated nares at a percentage of 6.25 $\%$. Exposure of dams to low-dose of IMI resulted in various malformations in head, chest and pelvic regions of the examined fetuses. The recorded visceral malformations were dilated nares (Fig. 3A), dilated brain ventricles (Fig. 3B), lung hypoplasia and intrathoracic hemorrhage (Fig. 3C) and dilated renal pelvis (Fig. 3D). Significant elevations $(\mathrm{P}<0.05)$ in the percentages of these malformations $(46.67 \%, 40 \%, 26.67 \%, 46.67 \%$ and $40 \%)$, respectively were recorded in LD-IMI group, compared to those of control group. The same anomalies (Fig. 4A, B, E), as well as, anophthalmia (Fig. 4C), cardiomegaly (Fig. 4D) and hypolpastic kidney (Fig. 4F) were recorded in fetuses of high-dose group. Significant increases in the percentages of dilated nares $(53.85 \%)$, dilated brain ventricles $(53.85 \%)$, lung hypoplasia $(38.46 \%)$, intrathoracic hemorrhage $(46.15 \%)$ and kidney anomalies $(61.54 \%)$ with insignificant increases in the percentages of anophthalmia (7.69\%) and cardiomegaly $(15.38 \%)$ were recorded in fetuses of HD-IMI group, when compared to those of control group. Although, there was a dose-dependent increase in the percentages of the mentioned visceral malformations, no significant changes were recorded between LD- and HD-IMI groups (Table 3). 
Table 3: Fetal Visceral Malformations of Control and Treated Dams

\begin{tabular}{|c|c|c|c|c|c|c|c|c|c|c|c|c|c|c|c|}
\hline \multirow{4}{*}{ Group } & \multirow{4}{*}{ 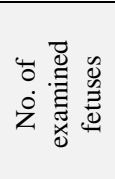 } & \multicolumn{14}{|c|}{ Malformations of } \\
\hline & & \multicolumn{6}{|c|}{ Head } & \multicolumn{6}{|c|}{ Chest } & \multirow{2}{*}{\multicolumn{2}{|c|}{$\begin{array}{c}\text { Pelvis } \\
\text { Kidney } \\
\text { anomalies }\end{array}$}} \\
\hline & & \multicolumn{2}{|c|}{$\begin{array}{c}\text { Dilated } \\
\text { nares }\end{array}$} & \multicolumn{2}{|c|}{ Anopthalmia } & \multicolumn{2}{|c|}{$\begin{array}{c}\text { Dilated } \\
\text { brain ventricle }\end{array}$} & \multicolumn{2}{|c|}{ Cardiomegaly } & \multicolumn{2}{|c|}{$\begin{array}{c}\text { Lung } \\
\text { hypoplasia }\end{array}$} & \multicolumn{2}{|c|}{$\begin{array}{l}\text { Intrathoracic } \\
\text { hemorrhages }\end{array}$} & & \\
\hline & & No & $\%$ & No & $\%$ & No & $\%$ & No & $\%$ & No & $\%$ & No & $\%$ & No & $\%$ \\
\hline Control & 16 & 1 & 6.25 & 0 & 0 & 0 & 0 & 0 & 0 & 0 & 0 & 0 & 0 & 0 & 0 \\
\hline LD-IMI & 15 & 7 & $46.67^{\mathrm{a}}$ & 0 & 0 & 6 & $40.00^{\mathrm{a}}$ & 0 & 0 & 4 & $26.67^{\mathrm{a}}$ & 7 & $46.67^{\mathrm{a}}$ & 6 & $40.00^{\mathrm{a}}$ \\
\hline HD-IMI & 13 & 7 & $53.85^{\mathrm{a}}$ & 1 & 7.69 & 7 & $53.85^{\mathrm{a}}$ & 2 & 15.38 & 5 & $38.46^{\mathrm{a}}$ & 6 & $46.15^{\mathrm{a}}$ & 8 & $61.54^{\mathrm{a}}$ \\
\hline
\end{tabular}

Data are presented as percentages of viscerally deformed fetuses in relation to the total number of the examined live fetuses. a: Significant difference between control and LD-IMI or HD-IMI groups at $\mathrm{P}<0.05$. LD-IMI: low dose-imidacloprid; HD-IMI: high dose- imidacloprid.

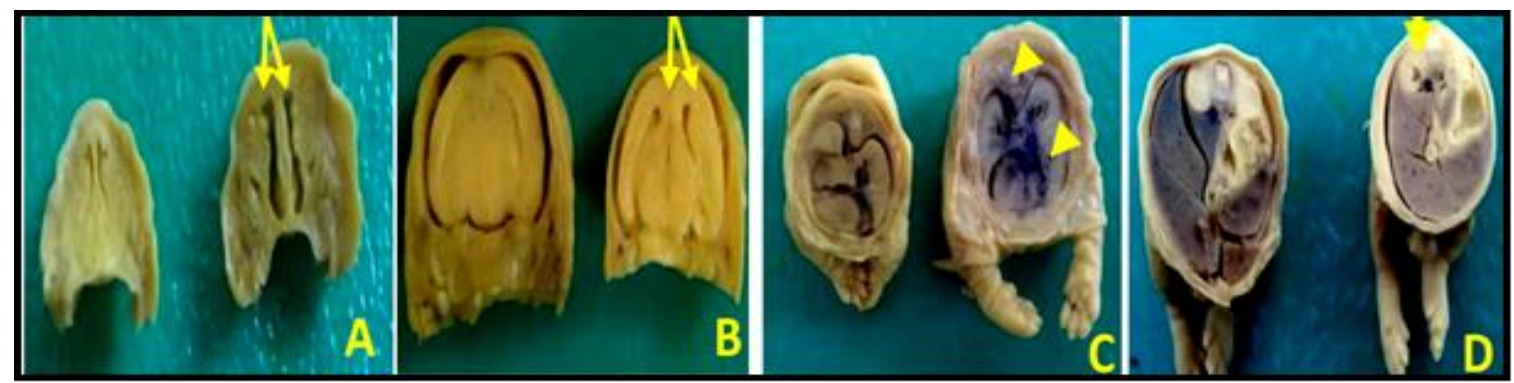

Fig. 3: Transverse Sections in Head (A, B), Chest (C) and Pelvis (D) of Rat Fetuses (Right) Obtained from Dams Treated Orally with Low Dose of IMI (45 Mg/Kg, 1/10 LD L $_{50}$ ) on Days 6-15 th of Gestation Showing: A: Dilated Nares, B: Dilated Brain Lateral Ventricles, C: Intrathoracic Hemorrhages and Lung Hypoplasia and D: Unilateral Dilatation of Renal Pelvis, Compared to Control (Left).

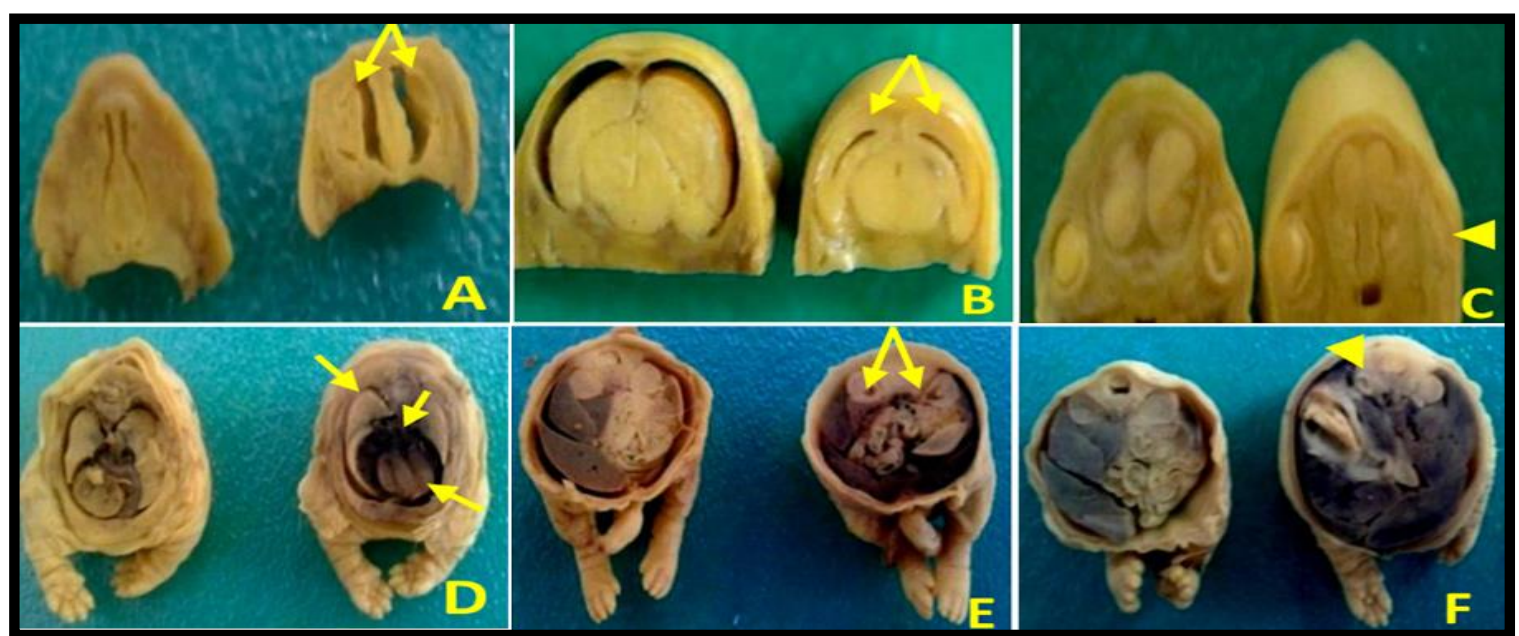

Fig. 4: Transverse Sections in the Head (A,B,C), Chest (D) and Pelvis (E,F) of Rat Fetuses (Right) Obtained from Dams Treated Orally with High Dose of IMI $\left(90 \mathrm{Mg} / \mathrm{Kg}, 1 / 5 \mathrm{LD}_{50}\right)$ on Days $6-15^{\text {th }}$ of Gestation Showing: A: Dilated Nares, B: Dilated Brain Lateral Ventricles, C: Anophthalmia D: Intrathoracic Hemorrhages, Hypoplasia of the Lung and Cardiomegaly, E: Bilateral Dilatation of Renal Pelvis and F: Hypoplasia of Right Kidney with Unilateral Dilatation of its Renal Pelvis, Compared to Control (Left).

\subsubsection{Fetal skeletal malformations}

As shown in Table (4), fetuses of control group showed only one fetus with wide open fontanel at a percentage of $3.57 \%$. Fetuses obtained from dams exposed to low-dose of IMI did not show marked skeletal malformations except insignificant increase $(\mathrm{P}<0.05)$ in the percentages of fetuses with wide open fontanel (11.54\%) and only one fetus showed hypoplastic sternbrae at a percentage of $3.85 \%$, compared to fetuses of control group. However, several skeletal malformations were recorded in fetuses of high-dose exposed dams. Regarding to control and low-dose groups, fetuses of HD-IMI group showed significant increases $(\mathrm{P}<0.05)$ in the percentages of wide open fontanel (63.64\%), incomplete ossification of skull (54.55\%), and absence of phalanges (63.6\%) (Fig. 5A), wavy and short ribs $(54.55 \%)$, and absence of caudal vertebrae (36.4\%) (Fig. 5B) and hypoplastic sternbrae (54.55\%) (Fig. 5C).

Table 4: Skeletal Malformations of Rat Fetuses from Control and Treated Dams

\begin{tabular}{|c|c|c|c|c|c|c|c|c|c|c|c|c|c|}
\hline \multirow[b]{4}{*}{ Group } & \multirow{4}{*}{ 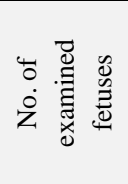 } & \multicolumn{12}{|c|}{ Malformations of } \\
\hline & & \multicolumn{4}{|c|}{ Skull Bones } & \multicolumn{2}{|c|}{ Sternum } & \multicolumn{2}{|c|}{ Ribs } & \multicolumn{2}{|c|}{ Phalanges } & \multicolumn{2}{|c|}{ Caudal vertebrae } \\
\hline & & \multicolumn{2}{|c|}{$\begin{array}{l}\text { Wide open } \\
\text { fontanel }\end{array}$} & \multicolumn{2}{|c|}{$\begin{array}{l}\text { Incomplete } \\
\text { ossification }\end{array}$} & \multirow[b]{2}{*}{ No. } & \multirow[b]{2}{*}{$\%$} & \multirow[b]{2}{*}{ No. } & \multirow[b]{2}{*}{$\%$} & \multirow[b]{2}{*}{ No. } & \multirow[b]{2}{*}{$\%$} & \multirow[b]{2}{*}{ No } & \multirow[b]{2}{*}{$\%$} \\
\hline & & No. & $\%$ & No. & $\%$ & & & & & & & & \\
\hline Control & 28 & 1 & 3.57 & 0 & 0 & 0 & 0 & 0 & 0 & 0 & 0 & 0 & 0 \\
\hline LD-IMI & 26 & 3 & 11.54 & 0 & 0 & 1 & 3.85 & 0 & 0 & 0 & 0 & 0 & 0 \\
\hline HD-IMI & 22 & 14 & $63.64^{\mathrm{a}, \mathrm{b}}$ & 12 & $54.55^{\mathrm{a}, \mathrm{b}}$ & 12 & $54.55^{\mathrm{a}, \mathrm{b}}$ & 12 & $54.5^{\mathrm{a}, \mathrm{b}}$ & 14 & $63.6^{\mathrm{a}, \mathrm{b}}$ & 8 & $36.4^{\mathrm{a}, \mathrm{b}}$ \\
\hline
\end{tabular}

Data are presented as percentages of skeletal deformed fetuses in relation to the total number of examined life fetuses. a: Significant difference between control and LD-IMI or HD-IMI groups and b: Significant difference between LD-IMI and HD-IMI groups at P $<0.05$. LD-IMI: low dose-imidacloprid; HD-IMI: high doseimidacloprid. 


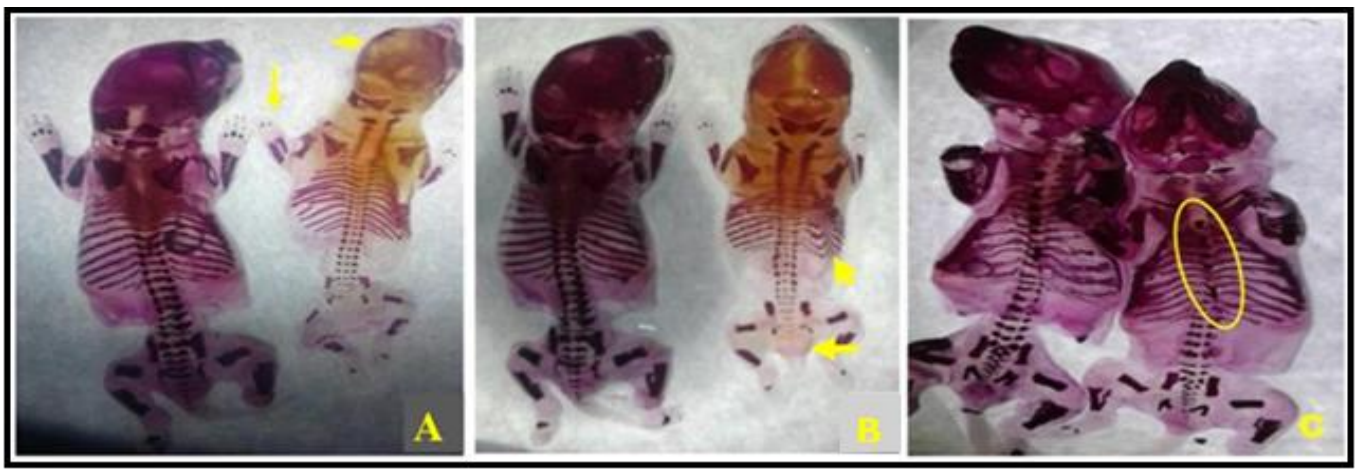

Fig 5: Rat Fetuses (Right) Obtained from Dams Treated Orally with High Dose of IMI $\left(90 \mathrm{Mg} / \mathrm{Kg}, 1 / 5 \mathrm{LD}_{50}\right)$ on Days 6-15 of Gestation Showing: A: Wide Open Fontanel and Incomplete Ossification of Skull, Absence of Phalanges, B: Wavy Ribs, Absence of Sacral and Caudal Vertebrae. C: Hypoplastic Sternbrae, Compared to Control (Left).

\subsection{Effects on oxidant/ antioxidant biomarkers}

\subsubsection{Serum of dams}

As recorded in Fig. (6), no significant differences $(\mathrm{P}<0.05)$ were observed in MDA, $\mathrm{H}_{2} \mathrm{O}_{2}$, GSH levels and CAT activity in serum of dams of LD-IMI group, compared to control group. However, there were significant increases $(\mathrm{P}<0.05)$ in $\mathrm{MDA}_{2} \mathrm{H}_{2} \mathrm{O}_{2}$ levels concurrently with significant reduction of GSH content and CAT activity in serum of dams of HD-IMI group as compared to control group. In comparing with low-dose group, dams of high-dose group showed significant changes in serum MDA level and CAT activity with insignificant changes in $\mathrm{H}_{2} \mathrm{O}_{2}$ and GSH levels.

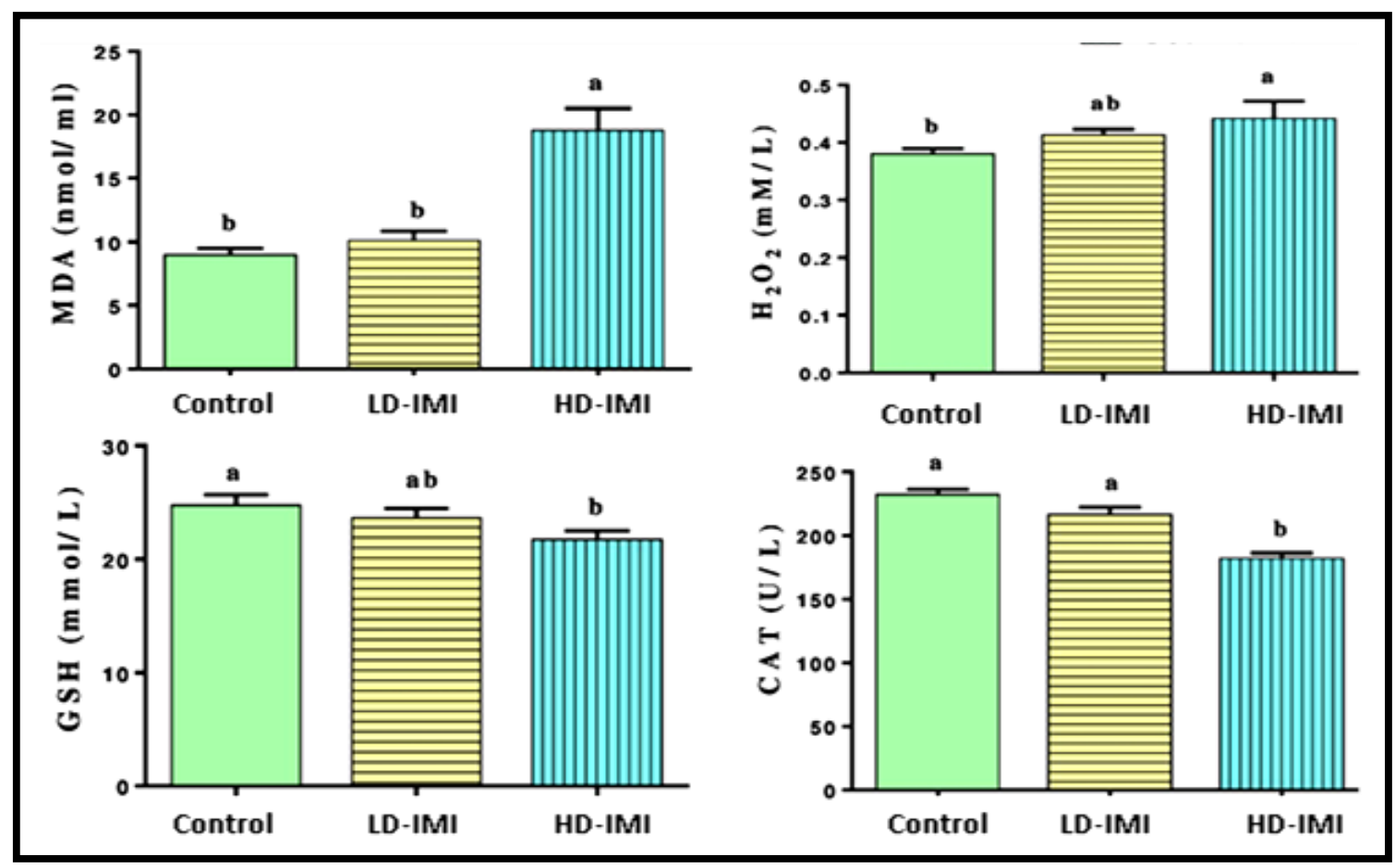

Fig. 6: Levels of Oxidant/ Antioxidant Biomarkers in Serum of Dams of the Different Groups.

Different letters indicate significant differences at $\mathrm{P}<0.05$. LD-IMI: low dose-Imidacloprid; HD-IMI: high dose- Imidacloprid.

\subsubsection{Placenta}

In placenta, the mean value of MDA level was significantly $(\mathrm{P}<0.05)$ elevated in a dose-dependent manner at low- and high-dose groups, while significant increase in $\mathrm{H}_{2} \mathrm{O}_{2}$ level was recorded only in high-dose group, when compared with those of control group (Fig. 7). Moreover, IMI administration caused significant $(\mathrm{P}<0.05)$ and dose-dependent decrease in GSH content and CAT activity in placenta, compared to those of control group. In comparing with low-dose group, placenta of high-dose group showed insignificant elevation in MDA level with significant increase in $\mathrm{H}_{2} \mathrm{O}_{2}$ level and significant reduction in GSH content and CAT activity. 


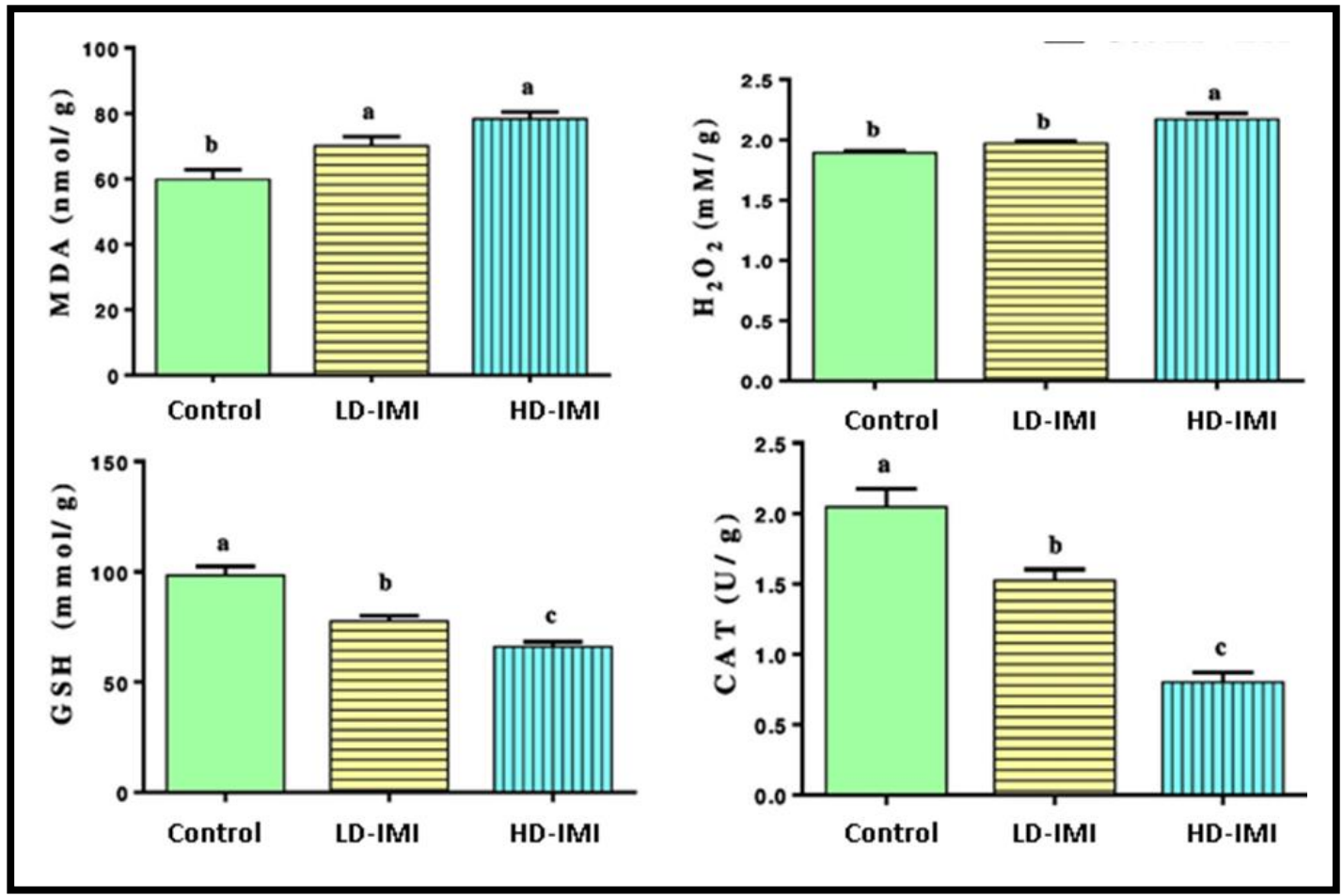

Fig. 7: Levels of Oxidant/ Antioxidant Biomarkers in Placenta of the Different Groups.

Different letters indicate significant differences at $\mathrm{P}<0.05$. LD-IMI: low dose-imidacloprid; HD-IMI: high dose- imidacloprid

\subsubsection{Liver of fetuses}

Referring to the results diagramed in Fig. (8), there was insignificant increase $(\mathrm{P}<0.05)$ in $\mathrm{MDA}$ and $\mathrm{H}_{2} \mathrm{O}_{2}$ levels in association with insignificant decrease in GSH content and CAT activity in liver of fetuses obtained from dams of LD-IMI group. However, there were significant changes in these parameters at high-dose level. Comparing to LD-IMI group, significant changes were recorded in the mean values of MDA level, GSH content and CAT activity in liver of fetuses at high dose, while no significant change was recorded in $\mathrm{H}_{2} \mathrm{O}_{2}$ level.

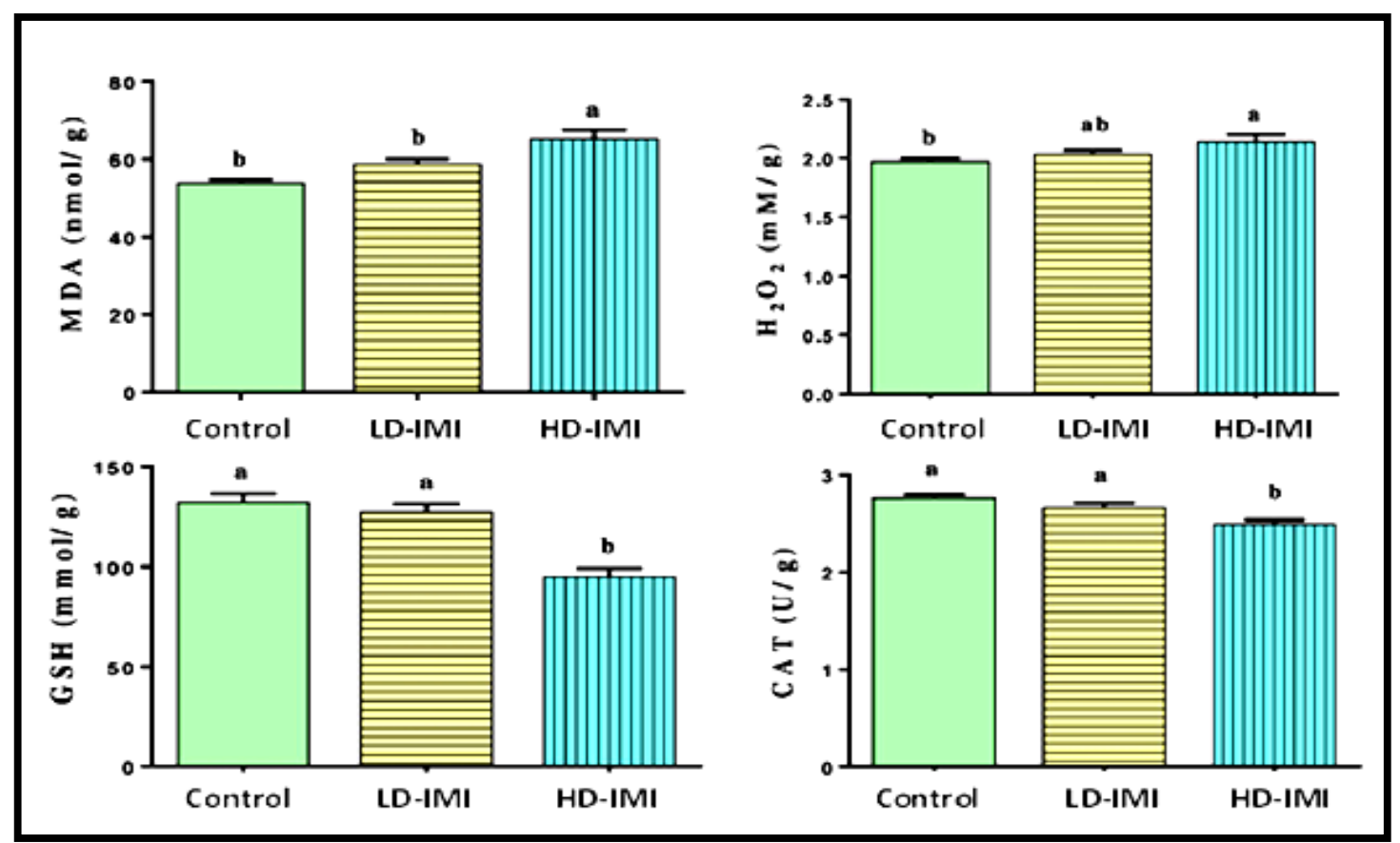

Fig. 8: Levels of Oxidant/ Antioxidant Biomarkers in Liver of Fetuses from Dams of the Different Groups. Different letters indicate significant differences at P<0.05. LD-IMI: low dose-Imidacloprid; HD-IMI: high dose- Imidacloprid.

\section{Discussion}

Imidacloprid (IMI), the most known neonicotinoid, is a moderately toxic compound (Matsuda et al., 2001). Although, it causes many toxic health hazards, the literatures available on its teratogenic effect are limited. Several investigations hypothesized the implication of 
oxidative stress in IMI- induced toxicity (Chakroun et al., 2017; Bashandy et al., 2017; El-Sabbagh et al., 2018). In the light of this background, this study aimed to evaluate the teratogenic effect of IMI and the potential mechanistic role of oxidative stress.

Our results confirmed that exposure to IMI induced significant increase in the percentage of resorptions at high dose and a dosedependent reduction in fetal and placental weights. Also, external fetal morphological and skeletal abnormalities were recorded only at high dose. Additionally, several visceral anomalies were observed at both low- and high- doses.

In consistent with our results, Gawade et al. (2013) reported that exposure of pregnant rats to IMI (10, $30 \mathrm{and} 90 \mathrm{mg} / \mathrm{kg} / \mathrm{day}, \mathrm{p}$. o.) caused a dose-dependent post implantation loss, still births and runts. Also, fetal morphological abnormalities and skeletal malformations included incomplete ossifications, wavy and fused ribs and absence of thoracic ribs were observed only at high dose (90 mg/kg b.w.). Conversely, no visceral malformations were recorded at any dose. Also, IMI induced growth retardation, developmental delays and malformations in chick embryo (Hussein et al., 2014).

Increasing evidences suggested the teratogenic effects of other neonecetenoids. Schardein, 1991 and Trutter, 1999 recorded that pregnant rats exposed to acetamiprid showed reductions in the number of implantations and fetal weight. As reviewed by Pfeil and Tasheva (2006), exposure to thiacloprid increased incidence of resorptions, decreased fetal weight, and increased incidence of skeletal malformations in rats. Also, reduction in placental weight in rabbits was previously recorded by Holzum (1996) and Stahl (1997).

Regarding to our results, the observed fetal malformations were accompanied by the recorded oxidative changes that induced after exposure of dams to IMI as evidenced by a dose- dependent increases in MDA and $\mathrm{H}_{2} \mathrm{O}_{2}$ levels with reductions in GSH content and CAT activity in serum of dams, placenta and liver of fetuses. Although, significant changes were recorded in placenta at both doses, the changes observed in serum of dams and liver of fetuses were significant only at high dose.

Our findings are consistent with previous studies that confirmed the ability of IMI to induce oxidative damages in various tissues (Duzguner and Erdogan, 2012; Ahmed and Nasr, 2015; Chakroun et al., 2017; El- Sabbagh et al., 2018). Also, several studies suggested the role of oxidative stress in the mechanisms of adverse imidacloprid effects on male and female reproduction (Kapoor et al., 2011; Bal et al., 2012; Lonare et al., 2016)

The recorded increase in MDA and $\mathrm{H}_{2} \mathrm{O}_{2}$ levels in serum of dams concomitant together with the decrease in GSH content and CAT activity could be attributed to excessive ROS generation induced by maternal exposure to IMI (Kapoor et al., 2010) that may be considered as one of the leading reasons to oxidative stress and lipid peroxidation and hence, oxidative tissue damages of the pregnant dams that may affect their offsprings.

The placenta, a functional connection between dam and the developing fetus, is essential for a proper progress of gestation and the development of a healthy offspring. It transmits the required nutrients for fetal development, eliminates fetal metabolic wastes and synthesizes the essential hormones for pregnancy (Desforges and Sibley, 2010). Therefore, impairments in its function lead to fetal growth retardation or, if more severe, birth defects and fetal death (Watson and Cross, 2005).

Chemical or drugs- induced placental damages subsequently may lead to resorptions, fetal growth retardation and teratogenicity (El Ghareeb et al., 2015). The recorded increase in the percentage of resorption sites, the marked reductions in placental and fetal weights and the observed fetal malformations could be attributed to the transplacental passage of IMI that induced placental oxidative damage. In confirmation with the present suggestion, previous reports assumed the penetration of placental barrier by neonicotinoids (Taira, 2014; Sheets et al., 2016).

The decrease in placental and fetal weights is sensitive and precise indicators for the developmental alterations in placental structures. Exposure of dams to IMI possibly induces oxidative placental injuries, and hence affects its nutritive role, resulting in resorptions or at least growth retardation. A smaller placenta probably has a lower blood flow, resulting in marked fetal hypoxia that may lead to retarded intrauterine growth (Houghton et al., 2000).

Oxidative stress (OS), a phenomena characterized by oxidant/ antioxidant imbalance, occurs as a consequent to over production of ROS, that exceeds the total cellular antioxidant capacity, and thus damages cellular components (Burton and Jauniaux, 2011). $\mathrm{MDA}_{\text {and }} \mathrm{H}_{2} \mathrm{O}_{2}$, free fatty acids oxidation products along with GSH and CAT, endogenous antioxidants, are sensitive biomarkers of oxidative tissue damage.

Redox status affects several cellular processes, including cell proliferation, differentiation, and signaling. Reactive oxidative species (ROS) play a remarkable role in fetal development. Oxidative stress and redox-related signaling are essential for normal developmental processes such as progression to the blastocyst stage, neuronal differentiation, and digit formation. Therefore, disability to elevate OS results in abnormal developmental sequences and dysregulations. Nevertheless, excess OS is substantially associated with teratogenicity (Dennery, 2007).

During definite periods in fetal development, the fetuses are more or less susceptible to teratogens that can alter redox status causing several biologically destructive effects (Sarker et al., 1995). Mounting evidence demonstrated that OS in uteroplacental tissues was implicated in the development of pregnancy complications (Jauniaux et al., 2006) and was associated with congenital malformations, reproductive defects, and infertility (Mathieu-Denoncourt et al., 2015).

The high metabolic activity of placental cells leads to ROS overproduction and placental oxidative stress (Myatt \& Cui 2004). Numerous placenta-related disorders are accompanied by increased placental oxidative stress (Coughlan et al., 2004; Jauniaux et al., 2006). Moreover, placental oxidative damage inhibits fetal growth (Nagai et al., 2008).

Another mechanism for the implication of oxidative stress in embryotoxicity, Wang et al. (2009) demonstrated that OS prevented the physiological function of P-glycoprotein that is involved in the function of blood-placental barrier and is critical in protecting fetus from drugs- and toxins- induced teratogenesis (Abu-Qare et al., 2003; Sun et al., 2006). 


\section{Conclusion}

Through these events we concluded that, exposure of pregnant dams during the period of organogenesis to IMI affects the maternal and fetal redox status, at a dose-dependent manner, confirming the ability of IMI to generate excessive ROS and its ability for trans-placental passage causing oxidative damage in placental and fetal tissues, as a consequent, cause fetal malformations. Taken together, these results suggest the implication of oxidative stress in IMI-induced teratogenicity. So, antioxidants may be used as pharmacological agents to pregnant dams to give promising protective benefits against fetal malformation and growth restriction induced by neonicotinoids and other insecticides.

\section{Acknowledgments}

All authors would gratefully thank the team of Central Lab, Faculty of Veterinary Medicine, University of Sadat City for their technical support in the implementation of this study.

\section{Disclosure of conflict of interest}

The author declares no conflicts of interest. The author had no financial grants or external fund.

\section{References}

[1] Abou-Donia MB, Goldstein LB, Bullman S, Tu T, Khan WA, Dechkovskaia AM and Abdel-Rahman AA (2008). Imidacloprid induces neurobehavioral deficits and increases expression of glial fibrillary acidic protein in the motor cortex and hippocampus in offspring rats following in utero exposure. J Toxicol Environ Health A 71(2), 119-30. https://doi.org/10.1080/15287390701613140.

[2] Abu-Qare AW, Elmasry E and Abou-Donia MB (2003). A role for P-glycoprotein in environmental toxicology. J Toxicol Environ Health B Crit Rev 6, 279-288. https://doi.org/10.1080/10937400306466.

[3] Adjrah Y, Karou SD, Agbonon A, Ameyapoh Y, de Souza C and Gbeassor M (2013). Effect of cypermethrin-treated lettuce (Lactuca sativa) on wistar rat liver. J. Appl. Pharmacol. Sci. 3, 128-132. https://doi.org/10.7324/JAPS.2013.30125.

[4] Aebi H. (1984). Catalase in vitro. Methods Enzymol. 105, 121-26. https://doi.org/10.1016/S0076-6879(84)05016-3.

[5] Ahmed MM and Nasr SA (2015). Protective Effect of Broccoli and Ferulic Acid on Imidacloprid-Induced Hepatotoxicity in Rat. The Egyptian Journal of Biochemistry \& Molecular Biology 33, 1-15. https://doi.org/10.21608/ejb.2015.9697.

[6] Anatra-Cordone M and Durkin P (2005). Imidacloprid. Human health assessment and ecological risk assessment Final report. Syracuse Environmental Research Associates, Inc., New York, SERA TR 05- 43-24-03a.

[7] Arfat Y, Mahmood N, Tahir MU, Rashid M, Anjum S, Zhao F, Li DJ, Sun YL, Hu L, Zhihao C, Yin C, Shang P and Qian AR (2014). Effect of imidacloprid on hepatotoxicity and nephrotoxicity in male albino mice. Toxicology Reports 1, 554-561 https://doi.org/10.1016/j.toxrep.2014.08.004.

[8] Bagri P, Kumar V and Sikka AK (2016). Assessment of imidacloprid- induced mutagenic effects in somatic cells of Swiss albino male mice. Drug Chem Toxicol. 39(4), 412-7. https://doi.org/10.3109/01480545.2015.1137301.

[9] Bal R, Türk G, Tuzcu M, Yilmaz O, Kuloglu T, Gundogdu R, Gür S, Agca A, Ulas M, Cambay Z, Tuzcu Z, Gencoglu H, Guvenc M, Ozsahin AD, Kocaman N, Aslan A and Etem E (2012). Assessment of imidacloprid toxicity on reproductive organ system of adult male rats. J Environ Sci Health B. 47(5), 434-44. https://doi.org/10.1080/03601234.2012.663311.

[10] Bashandy SA, Bashandy MA, El Zawahry EI, Adly F and Abdel Naby MF (2017). Beta Carotene and Hesperidin Antioxidants Mitigate Hepatotoxic Effects of Imidacloprid in Male Rats. Al Azhar Bulletin of Science 28(1), 15-27. https://doi.org/10.21608/absb.2017.8164.

[11] Beutler EK, Duron O and Kefly BM. (1963). Improved method for the determination of blood glutathione. J. Lab. Clin. Med. 61, 882-888.

[12] Bonmatin JM, Giorio C, Girolami V, Goulson D, Kreutzweiser DP, Krupke C, Liess M, Long E, Marzaro M, Mitchell AE, Noome DA, SimonDelso N, and Tapparo A (2015). Environmental fate and exposure; neonicotinoids and fipronil. Environ Sci Pollut Res Int. 22, 35-67. https://doi.org/10.1007/s11356-014-3332-7.

[13] Burton GJ and Jauniaux E (2011). Oxidative stress. Best Practice \&Research. Clinical Obstetrics \& Gynaecology 25, 287-299. https://doi.org/10.1016/j.bpobgyn.2010.10.016.

[14] Chakroun S, Grissa I, Ezzi L, Ammar O, Neffati F, Kerkeni E, Najjar MF, Haouas Z and Ben Cheikh H (2017). Imidacloprid enhances liver damage in Wistar rats: Biochemical, oxidative damage and histological assessment. Journal of Coastal Life Medicine 5(12), 540-546. https://doi.org/10.12980/jclm.5.2017J7-149.

[15] Coughlan MT, Vervaart PP, Permezel M, Georgiou HM and Rice GE (2004). Altered placental oxidative stress status in gestational diabetes mellitus. Placenta 25, 78-84. https://doi.org/10.1016/S0143-4004(03)00183-8.

[16] Desforges, M and Sibley CP (2010). Placental nutrient supply and fetal growth. Int. J. Dev. Biol. 54, 377-390. https://doi.org/10.1097/MCO.0b013e32835e3674.

[17] Duzguner V and Erdogan S (2012). Chronic exposure to imidacloprid induces inflammation and oxidative stress in the liver \& central nervous system of rats. Pesticide biochemistry and physiology 104(1), 58-64. https://doi.org/10.1016/j.pestbp.2012.06.011.

[18] El Ghareeb AEW, Hamdi H, Taha ESF and Ali H (2015). Evaluation of teratogenic potentials of bronchodilator drug on offsprings of albino rats. Int. J. Scient. Eng. Res. 6, 534-542. https://doi.org/10.14299/ijser.2015.03.005.

[19] El-Sabbagh HS, Khamiss OA, El-Borai NB and El-Khadrawey BA (2018). The Potential Therapeutic Value of Green Tea and Thyme Aqueous Extracts on Imidacloprid Toxicity in Rats, IJMPR 2(4), 59-67.

[20] Gawade L, Dadarkar SS, Husain R, and Gatne M (2013). A detailed study of developmental immunotoxicity of imidacloprid in Wistar rats. Food and Chemical Toxicology 51, 61-70. https://doi.org/10.1016/j.fct.2012.09.009.

[21] Goulson D. (2013): An overview of the environmental risks posed by neonicotinoid insecticides. J Appl Ecol. 50, 977-987. https://doi.org/10.1111/1365-2664.12111.

[22] Hamid S, Mahajan R and Singh H (2012). Carbaryl, A Pesticide Causes "Toxic Hepatitis in Albino Rats. J Cytol Histol 3 , 4. https://doi.org/10.4172/2157-7099.1000149.

[23] Holzum B (1996). YRC 2894 - Developmental toxicity study in rabbits after oral administration. Unpublished report No. 24709, edition No. M000780-01-1, dated 26 January 1996, from Bayer AG, Wuppertal, Germany. Submitted to WHO by Bayer CropScience AG, Monheim, Germany.

[24] Houghton PE, Mottola MF, Plust JH and Schachter CL (2000). Effect of maternal exercise on fetal and placental glycogen storage in the mature rat. Can. J. Applied Physiol. 25, 443-452. https://doi.org/10.1139/h00-029.

[25] Hussein M, Singh V, Hassan MA, Singh AK and Yadav B (2014). Malformations and Teratogenic Effects of Imidacloprid on Chick Embryo. Sch J. App. Med. Sci. 2(1A), 67-72.

[26] Jauniaux E, Poston L and Burton GJ (2006). Placental-related diseases of pregnancy: involvement of oxidative stress and implications in human evolution. Human Reproduction Update 12, 747-755. https://doi.org/10.1093/humupd/dml016. 
[27] Jeschke P, Nauen R, Schindler M and Elbert A. (2011). Overview of the status and global strategy for neonicotinoids. J Agric Food Chem 59(7):2897-908. https://doi.org/10.1021/jf101303g.

[28] Kapoor U, Srivastava MK and Srivastava LP (2011). Toxicological impact of technical imidacloprid on ovarian morphology, hormones and antioxidant enzymes in female rats. Food Chem Toxicol 49, 3086-9. https://doi.org/10.1016/j.fct.2011.09.009.

[29] Kapoor U, Srivastava MK, Bhardwaj S and Srivastava LP (2010). Effect of imidacloprid on antioxidant enzymes and lipid peroxidation in female rats to derive its No Observed Effect Level (NOEL). J Toxicol Sci. 35(4), 577-81. https://doi.org/10.2131/jts.35.577.

[30] Lonare M, Kumar M, Raut S, Badgujar P, Doltade S and Telang A (2014). Evaluation of imidacloprid-induced neurotoxicity in male rats: a protective effect of curcumin. Neurochem Int.78, 122-9. https://doi.org/10.1016/j.neuint.2014.09.004.

[31] Lonare M, Kumar M, Raut S, More A, Doltade S, Badgujar P and Telang A (2016). Evaluation of ameliorative effect of curcumin on imidaclopridinduced male reproductive toxicity in Wistar rats. Environ Toxicol 10, 1250-63. https://doi.org/10.1002/tox.22132.

[32] Manson GM, and Kang YG (1994). Test method for assessing female reproductive and developmental toxicology. In "Principles and Methods of Toxicology", 2nd Ed., by A. Wallace Hayes, Raven Press, Ltd., New York. https://doi.org/10.1201/b14258-38.

[33] Mathieu-Denoncourt J, Wallace SJ, de Solla SR and Langlois VS (2015). Plasticizer endocrine disruption: highlighting developmental and reproductive effects in mammals and non-mammalian aquatic species. Gen. Comp. Endocrinol. 219 , $74-88$. https://doi.org/10.1016/j.ygcen.2014.11.003.

[34] Matsuda K, Buckingham SD, Kleier D, Rauh JJ, Grauso M and Sattelle DB (2001). Neonicotinoids: insecticides acting on insect nicotinic acetylcholine receptors. Trends in Pharmacological Sciences 22(11), 573-580. https://doi.org/10.1016/S0165-6147(00)01820-4

[35] Mohany M, Badr G, Refaat I and El-Feki M (2011). Immunological and histological effects of exposure to imidacloprid insecticide in male albino rats. African Journal of Pharmacy and Pharmacology 5(18), 2106-2114. https://doi.org/10.5897/AJPP11.625.

[36] Myatt L and Cui X (2004). Oxidative stress in the placenta. Histochem Cell Biol 122, 369-382. https://doi.org/10.1007/s00418-004-0677-X.

[37] Nagai R, Watanabe K, Wakatsuki A, Hamada F, Shinohara K, Hayashi Y, Imamura R and Fukaya T (2008). Melatonin preserves fetal growth in rats by protecting against ischemia/ reperfusion-induced oxidative/nitrosative mitochondrial damage in the placenta. Journal of Pineal Research 45 , 271-276. https://doi.org/10.1111/j.1600-079X.2008.00586.x.

[38] Ohkawa H, Ohishi W and Yagi K. (1979). Assay for lipid peroxides in animal tissues by thiobarbituric acid reaction. Anal. Biochem. 95, 351- 358. https://doi.org/10.1016/0003-2697(79)90738-3.

[39] Otranto D, Colella V, Crescenzo G, Basano FS, Nazzari R, Capelli G, Petry G, Schaper R, Pollmeier M, Mallia E, Dantas-Torresa F and PaoloLi R (2016). Efficacy of moxidectin $2.5 \%$ and imidacloprid $10 \%$ in the treatment of ocular thelaziosis by Thelazia callipaeda in naturally infected dogs.Veterinary Parasitology 227, 118-121. https://doi.org/10.1016/j.vetpar.2016.07.035.

[40] Dennery PA (2007). Effects of Oxidative Stress on Embryonic Development. Birth Defects Research (Part C) 81,155-162. https://doi.org/10.1002/bdrc. 20098 .

[41] Paumgartten FJR, De-Carvalho RR, Souza K, Madi CAM and Chahoud I (1998). Study of the effectsof $\beta$-myrcene on rat fertility and general reproductive performance. Braz. J. Med. Biol. Res. 31, 955-965. https://doi.org/10.1590/S0100-879X1998000700012.

[42] Pfeil R and Tasheva M (2006). Thiacloprid. Thiacloprid X-X JMPR. Available from: apps.who.int/pesticide-residues-jmprdatabase/ Document/140.

[43] Sarker AH, Watanabe S, Seki S, Akiyama T and Okada S (1995). "Oxygen radical-induced single-strand DNA breaks and repair of the damage in a cell-free system," Mutation Research 337(2), 85-95. https://doi.org/10.1016/0921-8777(95)00012-9.

[44] Schardein JL (2011). Reproduction range-finding study in mated rats, 1991. Unpublished report No. $449-018$ from International Research and Development Corporation, Mattawan, MI, USA. Submitted to WHO by Nippon Soda Co., Ltd, Tokyo, Japan. In: Kanungo D, and Solecki R. 2011. Acetamiprid. In Pesticide Residues in Food. Toxicological Evaluations. Joint FAO/Who Meeting on Pesticide Residues. Geneva, Switzerland 2029, 3-92.

[45] Sheets LP, Li AA, Minnema DJ, Collier RH, Creek MR and Peffer RC (2016). A critical review of neonicotinoid insecticides for developmental neurotoxicity. Crit Rev Toxicol 46(2), 153-190. https://doi.org/10.3109/10408444.2015.1090948.

[46] Simon-Delso N, Amaral-Rogers V, Belzunces LP, Bonmatin JM, Chagnon M, Downs C, et al. (2015). Systemic insecticides (neonicotinoids and fipronil): trends, uses, mode of action and metabolites. Environ Sci Pollut Res Int 22(1), 5-34. https://doi.org/10.1007/s11356-014-3470-y.

[47] Singh S, Pandey A, Sharma B, Lawrence K and Pandit S (2013). Imidacloprid induced osmotic fragility in erythrocytes of rats: Protective role of vit.C and tea. IOSR Journal of Environmental Science, Toxicology and Food Technology 5 (5), 103-105. https://doi.org/10.9790/2402-055103105.

[48] Stahl B (1997). YRC 2894 -Developmental toxicity in rats after oral administration. Unpublished report No. 26132, edition No. M-000832-01-1, dated 25 March 1997, from Bayer AG, Wuppertal, Germany. Submitted to WHO by Bayer CropScience AG, Monheim, Germany.

[49] Sun M, Kingdom J, Baczyk D, Lye SJ, Matthews SG and Gibb W (2006). Expression of the multidrug resistance P-glycoprotein, (ABCB1 glycoprotein) in the human placenta decreases with advancing gestation. Placenta 27(6/7), 602-609. https://doi.org/10.1016/j.placenta.2005.05.007.

[50] Taira K (2014): Human neonicotinoids exposure in Japan. Jpn J Clin Ecol. 23 (1),14-24.

[51] Tomizawa M and Casida JE (2005). Neonicotinoid insecticide toxicology: mechanisms of selective action. Annu Rev Pharmacol Toxicol. 45, 24768. https://doi.org/10.1146/annurev.pharmtox.45.120403.095930.

[52] Trutter JA (2011). Two-generation reproduction study with NI-25 in rats (reproduction and fertility effects), 1999. Unpublished report No. Covance 6840-108 from Covance Laboratories Inc., Vienna, VA, USA. Submitted to WHO by Nippon Soda Co., Ltd, Tokyo, Japan, 1999. In: Kanungo D, and Solecki R. 2011. Acetamiprid. In Pesticide Residues in Food. Toxicological Evaluations. Joint FAO/Who Meeting on Pesticide Residues. Geneva, Switzerland 20-29, 3-92.

[53] Vohra P and Khera KS (2015): A Three Generation Study with Effect of Imidacloprid in Rats: Biochemical and Histopathological Investigation. Toxicol Int. 22(1): 119-124. https://doi.org/10.4103/0971-6580.172270.

[54] Wang T, Chen M, Yan YE, Xiao FQ, Pan XL and Wang H (2009). Growth retardation of fetal rats exposed to nicotine in utero: Pos sible involvement of CYP1A1, CYP2E1, and P-glycoprotein. Environ Toxicol 24, 33-42. https://doi.org/10.1002/tox.20391.

[55] Watson ED and Cross JC (2005). Development of structures and transport functions in the mouse placenta. Physiology (Bethesda) $20,180-193$. https://doi.org/10.1152/physiol.00001.2005 